\title{
Chapter 7 \\ Theoretical Foundations of Biodiversity and Mental Well-being Relationships
}

\author{
Melissa R. Marselle
}

\begin{abstract}
This chapter briefly describes six frameworks that offer perspective on the relationships between biodiverse natural environments and mental well-being. The aim of this chapter is to provide an overview of these frameworks to enable theoretical grounding of future biodiversity and mental well-being studies. The frameworks are largely from the field of environmental psychology and represent the majority of theories used in biodiversity and health research (The Preference Matrix; fractal geometry; the Biophilia Hypothesis; Stress Reduction Theory; Attention Restoration Theory; and Ecosystem Service Cascade Model). A general overview of each framework discusses its conceptualisation of biodiversity and mental well-being outcomes, with supporting empirical research. The chapter then summarises the six frameworks with regard to their hypotheses for biodiversity and mental well-being.
\end{abstract}

Keywords Mental well-being · Biodiversity · Theory $\cdot$ Ecosystem services · Attention restoration theory $\cdot$ Stress reduction theory

\section{Highlights}

- Six frameworks provide perspective into biodiversity and mental well-being relationships.

- There is no single framework to describe biodiversity and mental well-being relationships.

- Further research is needed to test these frameworks using biodiverse environments or stimuli.

\footnotetext{
M. R. Marselle $(\bowtie)$

Department of Ecosystem Services, Helmholtz Centre for Environmental Research - UFZ, Leipzig, Germany

German Centre for Integrative Biodiversity Research (iDiv) Halle-Jena-Leipzig,

Leipzig, Germany

e-mail: melissa.marselle@ufz.de
} 


\subsection{Introduction}

Biodiversity affects human health and well-being in a variety of ways (Lindley et al. Chap. 2; Cook et al. Chap. 11, both in this volume). It supports the ecosystem services that help to preserve people's health through regulating clean air and water, and providing food, medicine, shelter, clothing and heat (Mace et al. 2012; World Health Organization and Secretariat of the Convention on Biological Diversity 2015). Biodiversity also helps to mitigate the negative effects of climate change on human health (see Lindley et al. Chap. 2, this volume). Yet, biodiversity (with climate change) can also harm human health by discharging pollen and increasing contact with organisms carrying diseases (Vaz et al. 2017; see also Damialis et al. Chap. 3 and Müller et al. Chap. 4 in this volume). In addition to these impacts of biodiversity on physical health, biodiverse environments also affect mental health (see de Vries \& Snep, Chap. 8, Marsell et al. Chap 9 both in this volume) and spiritual well-being (see Irvine et al. Chap 10 this volume). Researchers working in this emerging interdisciplinary field use existing frameworks, often from the field of environmental psychology, to explain these associations. The aim of this chapter is to provide an overview of these frameworks to enable theoretical grounding of future biodiversity and mental health and well-being studies. This chapter briefly describes six of the most widely used frameworks that offer perspective on the relationships between biodiverse natural environments and mental health and wellbeing, and related empirical research. These frameworks include the Preference Matrix; fractal geometry; the Biophilia Hypothesis; Stress Reduction Theory; Attention Restoration Theory; and the Ecosystem Service Cascade Model. The final section summarises these six frameworks and discusses a way forward.

\subsection{Environmental Preference}

Liking or preferring one thing over another influences behaviours. For example, preference for one environment over another may influence where to have a picnic, which house to buy or whether one supports nature conservation. Environmental preference frameworks examine relationships between physical characteristics of a landscape (e.g. urban vs. natural, water, land use type, open spatial arrangement, spatial definition, tree size, tree density) and psychological judgements of preference or aesthetic value (Kaplan and Kaplan 1989; Hartig and Evans 1993). Whilst these frameworks do not consider links to health and well-being, they are nevertheless included here, as preference for a specific environment may indicate the potential that environment could have on well-being (Hartig and Evans 1993; Hartig et al. 2011). 


\subsubsection{Aesthetic Model of Preferences}

Berlyne's $(1960,1974)$ aesthetic model states that aesthetic responses are a function of four properties of a visual stimulus and the behaviour evoked by those stimuli. Importantly for this chapter, one of those properties is complexity, which is the variety of components that make up the environment (Bell et al. 2001; Ulrich 1983). High complexity in a visual stimulus is characterised by a large number of elements and the dissimilarity among them (Ulrich 1983). According to Berlyne's aesthetic model, preference is related to complexity in an inverted U-shape (Berlyne 1960, 1974). Environments with moderate levels of complexity are hypothesised to be most preferred, whereas environments with high or low complexity would be less preferred (Bell et al. 2001; Ulrich 1983). Testing this hypothesis, Wohlwill (1968) found that preference was greatest for environments with intermediate levels of complexity.

\subsubsection{Preference Matrix}

The Preference Matrix (Kaplan and Kaplan 1989) is an informational model of environmental preference which posits that preferences for environments are based on information that the environment provides. According to this framework, the foundation of environmental preferences is the desire to obtain information from the environment. As such, environments that support rapid information processing, understanding and exploration will be preferred (Hartig and Evans 1993).

In the Preference Matrix, four informational qualities in a landscape are ordered by the visitor's need for information and the level of interpretation required to obtain that information (see Table 7.1). The coherence of the various stimuli in the environment, and how they all fit together, will support immediate understanding of an environment. Coherence provides a sense of order, which contributes to one's ability to quickly understand an environment; it can be enhanced through redundant features, such as repeating patterns or uniformity of texture (Kaplan and Kaplan 1989). Exploration of the immediate environment depends on the complexity of the stimuli: "the number of different visual elements in a scene; how intricate the scene is; its richness" (Kaplan and Kaplan 1989, p. 53). Complexity in this context refers to how much there is to look at and think about; too much complexity and the environment cannot be understood and is confusing, but too little complexity and the individual is bored and not motivated to explore. Making sense of an inferred or

Table 7.1 The preference matrix (Kaplan and Kaplan 1989)

\begin{tabular}{l|l|l}
\hline & \multicolumn{2}{|c}{ Informational needs } \\
\hline Level of interpretation & Understanding & Exploration \\
\hline Immediate & Coherence & Complexity \\
\hline Inferred, predicted & Legibility & Mystery \\
\hline
\end{tabular}


predicted environment, one that is currently out of view, requires two information qualities. Legibility helps facilitate understanding of the environment. A legible environment is "easy to understand and to remember" (Kaplan and Kaplan 1989, p. 55) and suggests that one can proceed further into the environment without getting lost. Features of legibility include landmarks and trails. Mystery is the promise of additional information with a change of vantage point, the possibility of more information just around the corner. Mystery encourages future involvement (there is some partially hidden information) and continued exploration of the environment (to find out what it is, what is over there). Features of mystery include a bend in a path, partial obstruction of a view, or a modest change in environmental features (Kaplan and Kaplan 1989).

\subsubsection{Connection to Biodiversity in the Preference Matrix}

In the Preference Matrix, biodiversity is implicitly mentioned as complexity; Kaplan and Kaplan (1989, p. 53) discuss an environment's "diversity" and "richness" when describing this information quality. Van den Berg et al. (2016) investigated whether perceived complexity of natural and urban scenes would explain differences in viewing times and ratings of mental restoration (a composite measure assessing fascination, beauty, relaxation, positive affect) (see Sect. 7.3.2 for further discussion on these concepts). Perceived complexity in this study was assessed as the number of different elements to see in the environment. Participants rated natural scenes as more complex than urban scenes. Further, within the type of environment, viewing times and mental restoration differed according to the complexity of the environment. More complex natural scenes with "information-rich tree-tops and forest" were viewed longer and rated as more restorative, than less complex natural scenes with shrubs and fields (van den Berg et al. 2016, p. 400). The authors suggest that complexity may be an important indicator of a scene's restorative potential.

\subsubsection{Fractal Geometry and Visual Fluency}

The term fractal is used to describe shapes, processes or systems that contain repeating patterns that are reduced-size copies of the whole (Bourke 1991; Ibanez and Bockheim 2013). As such, the defining feature of fractals is self-similarity; a "shape is made of smaller copies of itself...same shape but different size" (Frame et al. n.d.). This self-similarity can be identified and quantified by the fractal dimension, $D$. The equation for fractal dimension, $D$, is $\log \left(N^{R}\right) / \log \left(1 / S^{R}\right)$, where $N$ equals the number of line segments in the pattern, $S$ is the scale factor, and $R$ is the number of recursions of the pattern (Bies et al. 2016). For example, a fractal line will have a fractal dimension $D$ score that is between 1.0 and 2.0, whilst a fractal surface will have a $D$ score between 2.0 and 3.0 (Hagerhall et al. 2004). 


\subsubsection{Connection to Biodiversity with Fractals}

Benoit Mandelbrot's (1983) book the "The Fractal Geometry of Nature" applied fractal geometry to common natural phenomena, such as coastlines, rivers, trees, leaves and snowflakes. The book argues that fractals are an essential tool for understanding the natural world (Mandelbrot 1983). Mandlebrot (1983, p. 1) reasoned that "clouds are not spheres, mountains are not cones, coastlines are not circles, and bark is not smooth, nor does lightning travel in a straight line", but are rather comprised of fragmented, self-similar repeated patterns. Figure 7.1 shows examples of fractals that occur in nature.

Ecologists have used fractal geometry to determine the biodiversity of an environment (Tokeshi and Arakaki 2012). The fractal dimension, D, has been used to determine habitat quality (Imre and Bogaert 2004), landscape structure and composition (Pe'er et al. 2013), habitat complexity (Dibble and Thomaz 2009) and species richness (Stevens 2018). The relative lack of fractals has been used to identify manmade landscapes (Pe'er et al. 2013). Irme and Bogaert (2004) used fractals to determine the habitat quality of 49 pine tree (Pinus sylvestris L.) woodlots in Belgium. The authors hypothesised that if the woodlots were created due to habitat fragmentation - the process through which large habitats are broken up into small parcels - then the fractal dimensions of the boundaries of these habitats should all be similar (Imre and Bogaert 2004). Fractal similarity for the boundary shape of the woodlots was found, highlighting that the 49 patches of woodland were once one large pine forest and were created as a result of habitat fragmentation. Dibble and Thomaz (2009) examined whether fractal dimension $D$ scores could quantitatively describe the complexity of 11 species of aquatic plants, and if the $D$ score could be used to predict density of invertebrates found within these aquatic plants. $D$ scores were a good predictor of plants' complexity; plant species with high numbers of finely dissected leaves or roots had higher $D$ scores compared to plants with single leaves. Furthermore, a significant relationship was found between $D$ score and density of invertebrates; more complex plants, as measured by $D$ score, were associated with a greater number of invertebrates. Stevens (2018) investigated whether fractal dimensions of the tree silhouette of a habitat would differ based on the species richness of plants, animals and fungi in that habitat. There was a significant difference in $D$ scores between high or low species rich habitats; $D$ scores were higher in tree silhouettes of high species-rich habitats compared to tree silhouettes of low speciesrich habitats.

\subsubsection{Fractal Dimension and Preference}

Could the fractal dimension $D$ predict environmental preference? Initially, inconsistent results were found, with studies showing preference for fractal patterns with both high and low $D$ scores (Taylor 2001). Thinking that perhaps this inconsistency was related to the source of the $D$ scores, Spehar et al. (2003) investigated preference for fractals generated by nature (e.g. trees, mountains, clouds), human beings 

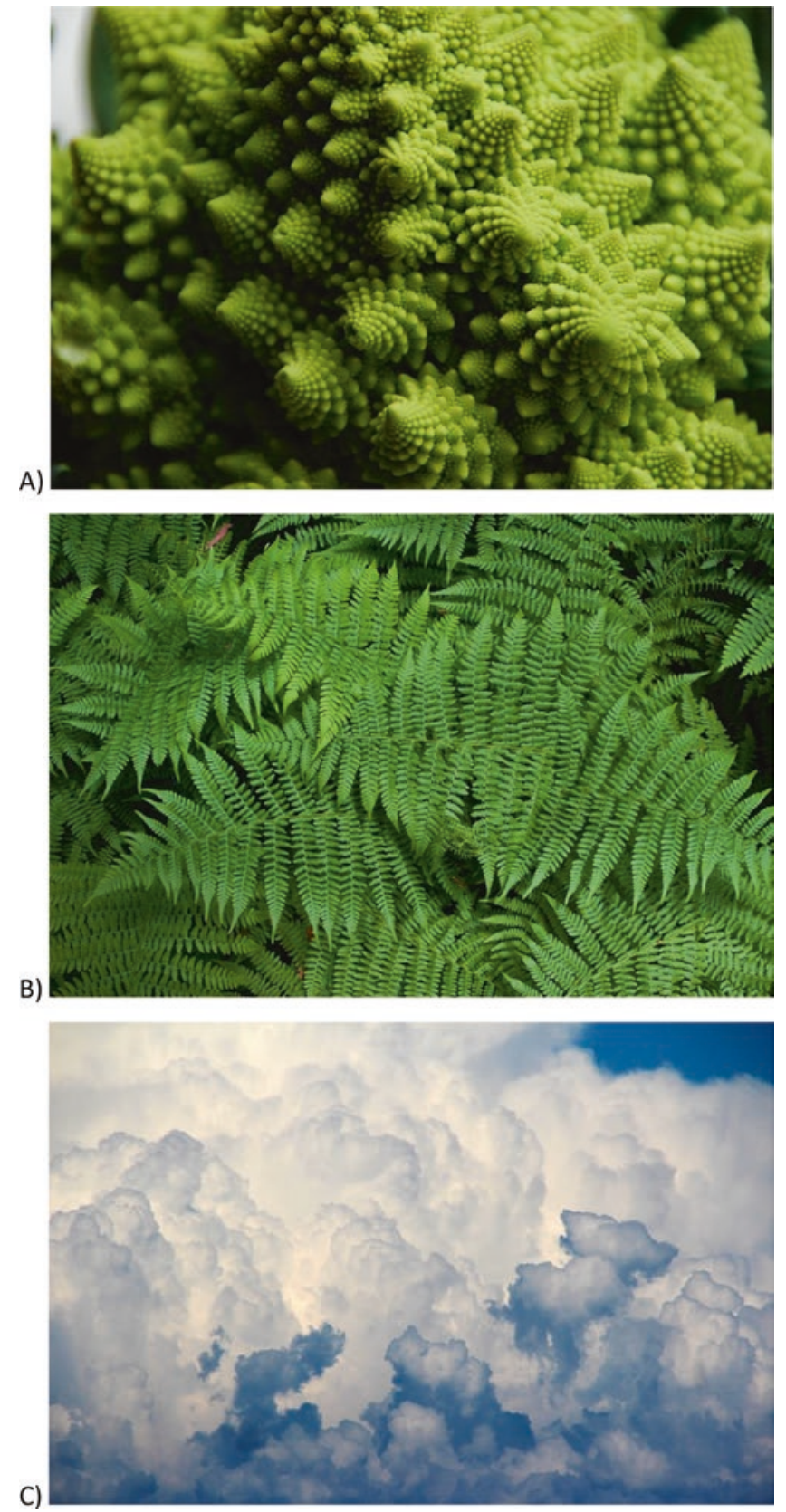

Fig. 7.1 Pictures of natural fractals, demonstrating self-similarity in which a repeated pattern is a reduced-size copy of the whole. (a) A Romanesco broccoli (by cyclonebill, CC BY-SA 2.0, https:// commons.wikimedia.org/w/index.php?curid=8818018), (b) Lady Ferns (Athyrium filix-femina) (by Sanjay Ach, CC BY-SA 3.0, https://commons.wikimedia.org/w/index.php?curid=2169955) and (c) Clouds (by 3dman_eu, CC0, https://pixabay.com/en/clouds-sky-cloud-dark-clouds-1473311) 
(e.g. a Jackson Pollock painting) or computer simulation. They found that fractal patterns with a mid-range $D$ score around $1.3-1.5$ were aesthetically preferred, irrespective of whether they were natural, human or computer generated (Spehar et al. 2003). Further support for preference for mid-range $D$ scores was found in Bies et al.'s (2016) study investigating preferences for statistical (fractals that do not repeat exactly but have the same statistical qualities, like those found in nature) or exact (fractal patterns that repeat precisely, created by a computer programme) fractals. For statistical fractals mid-range $D$ scores were preferred, whilst for exact fractals a higher $D$ score was preferred (Bies et al. 2016). Interestingly, the mid-range $D$ score of 1.3 is most prevalent in nature (Hagerhall et al. 2004, 2015), and found in species-rich habitats (Stevens 2018). These results fit with the environmental perception and preference theories that posit that intermediate levels of perceived visual complexity are most preferred (Kaplan and Kaplan 1989; Berlyne 1960, 1974; Wohlwill 1968) (see Sects. 7.2.1 and 7.2.2).

\subsubsection{Fractal Dimension and Restorative Outcomes}

One reason fractals are preferred could be due to perceptual fluency - the ease with which a specific visual stimulus is perceptually processed (Joye and van den Berg 2013). Fractal characteristics of visual stimuli contain redundant information, due to their self-similar repeating patterns, which could contribute to the experience of easy perceptual processing by the brain. This 'perceptual fluency' could result in restorative outcomes, such as attention restoration (Joye and van den Berg 2013) (see Sect. 7.3.2). Natural stimuli with fractal geometry may be processed more easily, resulting in lower cognitive resource demands of directed attention (Joye and van den Berg 2013) (see Sect. 7.3.2). This easier processing of natural stimuli may contribute to the restoration of directed attention (Joye and van den Berg 2013). Specifically testing the perceptual fluency hypothesis, Joye et al. (2016) investigated the effect that viewing fractal stimuli would have on cognitive performance. Participants were asked to complete a cognitively effortful task whilst viewing either high fractal or low fractal computer-generated (non-nature) stimuli. Participant's cognitive performance was better in the high fractal condition than in the low fractal condition ( $D$ scores were not assessed). Participants also perceived the cognitive tasks to be easier when looking at the high fractal stimuli, lending support to the perceptual fluency hypothesis.

Would fractals with a mid-range $D$ score contribute to perceptual fluency? Juliani et al. (2016) found that people were best at navigating through virtual, computergenerated fractal landscapes with $D$ scores between 1.1 and 1.3. Hagerhall et al. (2015) investigated participants' brain activity while viewing statistical or exact fractals. Participants' alpha brain waves were recorded as they looked at these fractal patterns. Alpha brain waves indicate a "wakefully relaxed state" and are commonly found when a person has their eyes closed and their attention directed inward 
on mental imagery (Hagerhall et al. 2015, p. 3). The authors found that the brain responded differently to statistical and exact fractals. Statistical fractals resulted in the highest alpha waves in the brain, suggesting that they attract effortless attention, enabling the mind to think about other things (Hagerhall et al. 2015). Taylor et al. (2011) tracked participants' eye movements with eye-tracking technology as they scanned a Jackson Pollock painting. The eye movement trajectories, themselves, had a $D$ score of 1.4 , and were not related to the $D$ score of the Pollock painting being observed. The authors suggest that fractal patterns with mid-range $D$ scores of 1.5 have a 'resonance' with the brain's own visual processing, which could contribute to the experience of perceptual fluency. This match between the fractal dimensions of the image and the brain's visual processing could account for aesthetic preference (Taylor et al. 2011).

\subsubsection{Biophilia Hypothesis}

Biophilia is "the innately emotional affiliation of human beings to other living organisms" (Wilson 1993, p. 31). This affiliation motivates humans to seek contact with animals, plants and landscapes (Sundli Tveit et al. 2013). The Biophilia Hypothesis emphasises human beings' positive response to nature, which can be manifest as a preference for specific animals, plants or environments (Hartig et al. 2011). Defining features of the Biophilia Hypothesis are highlighted in Box 7.1.

The Biophilia Hypothesis posits there is an innate, genetic basis for this affiliation with nature (Wilson 1984, 1993). Biological evolution is the process of continuous genetic adaptation to the environment; organisms that are better suited to the environment have a higher survival rate, which gives a genetic advantage compared to organisms that are less suited to their environment. As such, personenvironment interactions that have an adaptive value will be genetically retained (Wilson 1984, 1993). Genetic adaptation to the environment arises from behaviours learned through human-nature interactions (Wilson 1993). Interacting with nature results in learnt emotional responses, which can range from attraction to aversion, from peacefulness to anxiety (Wilson 1993). Behavioural responses, such as approaching or avoiding a stimulus, result from these emotions (Wilson 1993).

\section{Box 7.1: Defining Features of the Biophilia Hypothesis}

- Humans have an innate, emotional connection to life and life-like processes

- This affinity motivates contact with animals, plants and natural landscapes

- Emphasises positive responses to nature, manifest as preference for nature 
These emotional and behavioural responses to stimuli in the natural environment, such as the fear/avoidance response to snakes or to approach response to clean water sources, contribute to survival. This is called biologically prepared learning, in which, through evolution, humans have retained quick emotional and behavioural responses to specific natural stimuli (Ulrich 1993). These emotional outcomes and concomitant behavioural responses (approach vs. avoid) from natural stimuli are then transmitted through culture (e.g. the cultural symbolism of a snake as dangerous) (Wilson 1993). Biologically prepared learning to avoid certain natural stimuli is called biophobia (Ulrich 1993).

Criticisms of Biophilia exist (Kahn 1997; Joye and de Block 2011). First, the Biophilia Hypothesis is considered so general that any research studies on the relationship between human beings and natural environments - from human communication, cognitive and mental development, and aesthetic appreciation, to companion animals, learning survival skills, and environmental ethics - are considered as evidence for testing the Biophilia Hypothesis, even if the researcher is testing other theories (Kellert 1993, p. 22). Furthermore, the Biophilia Hypothesis is argued to be more of a general concept, rather than a theory with testable hypotheses (Joye and de Block 2011, p. 193); there is no model describing how connection to plants, animals and landscapes influences human communication, cognitive and mental development, and aesthetic appreciation. Whilst learning theory (Wilson 1993; Ulrich 1993) is proposed as a mechanism, it is unclear if learning theory can account for all outcomes, or if additional mediators are required. Additional criticisms are whether biophilia is innate (Kahn 1997; Joye and de Block 2011), and if biophobia contradicts the Biophilia Hypothesis (Kahn 1997).

\subsubsection{Connection to Biodiversity in the Biophilia Hypothesis}

The Biophilia Hypothesis emphasises human beings' positive response to nature, which can be manifest as a preference for animals, plants and natural landscapes. Furthermore, the Biophilia Hypothesis also considers the impacts to health and well-being due to biodiversity loss (Wilson 1993; Ulrich 1993). Unfortunately, the Biophilia Hypothesis does not specify which species or landscape types best fulfil people's biophilic needs (Sundli Tveit et al. 2013). The strongest work on Biophilia Hypothesis is on its converse, biophobia (Hartig et al. 2011).

Empirical support for Biophilia largely comes from studies investigating biodiversity and preference relationships. People prefer more biodiversity (LindemannMatthies et al. 2010). Hedblom et al. (2014) found preference was greater for birdsong from seven different species of birds than for birdsong from one bird species. Cracknell et al. (2017) found that people preferred viewing an aquarium with a high number of different species of fish/crustaceans, compared to the viewing an aquarium with a low number of different species. Johansson et al. (2014) explored the effect of three different levels of biodiversity (low, medium and high) in forest biotopes on preference ratings. An inverted U-shape was found for preference; the medium biotope was the most preferred followed by the high biotope and the low biotope (Johansson et al. 2014). This suggests that more biodiversity may be pre- 
ferred up to a limit (see Sects. 7.2.1 and 7.2.2 for further discussion on why intermediate levels of biodiversity might be most preferred).

\subsection{Theories of Restorative Environments}

Restoration refers to the recovery of physiological or psychological resources that have been diminished through the demands of dealing with everyday life (Hartig et al. 2011). Physiological resources are the ability to mobilise energy toward a specific demand, such as running to catch a train home or working hard to meet a deadline. Psychological resources include the ability to focus attention in order to concentrate on a particular task. Without restoration of these resources, a person is unable to cope with new demands (imagine working to meet a new deadline with depleted physiological and psychological resources immediately after meeting the last deadline). Over time, lack of restoration of these resources can lead to mental and physical ill health (Hartig et al. 2011; von Lindern et al. 2016). Environments that facilitate the recovery and restoration of these depleted resources are called restorative environments. This section describes the two theories of restorative environments.

\subsubsection{Stress Reduction Theory (SRT)}

The Stress Reduction Theory (SRT) (Ulrich 1983; Ulrich et al. 1991) considers the physiological impact from viewing natural environments. Box 7.2 summarises the defining features of SRT. According to the theory, natural environments facilitate restoration from stress. Outcomes of restoration are reduced physiological arousal, psychological stress, and negative affect, and enhanced positive affect (Ulrich et al. 1991). Individuals who are stressed are most likely to experience reduced physiological arousal through contact with nature, whilst unstressed individuals are most likely to experience improved affect (Hartig and Evans 1993).

\section{Box 7.2: Defining Features of the Stress Reduction Theory}

- Natural environments benefit health by faciliating recovery from stress

- Stress recovery is manifest as reduced physiological arousal, psychological stress and negative affect, and enhanced positive affect

- Visual characteristics of restorative environments are: moderate complexity; moderate depth; a focal point; deflected vistas (e.g. path bending away); a ground surface conducive for movement; lack of threat; and water

- Biodiversity is considered to be a measure of an environment's complexity 
Fig. 7.2 Simplified version of the Stress Reduction Theory of affective/arousal response to a natural environment. (Based on Ulrich 1983)

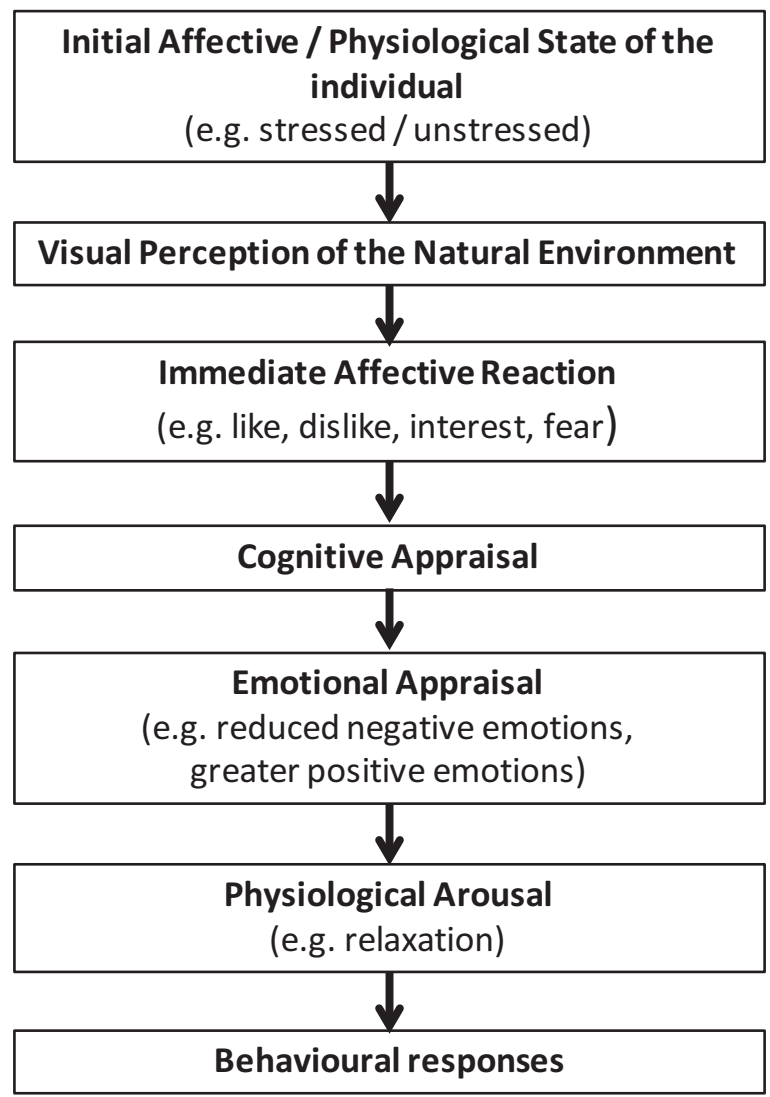

The SRT details a sequential process in which viewing a natural scene has an effect on one's feelings and behaviour, largely through the autonomic nervous system (Irvine et al. 2013, p. 420) (see Fig. 7.2). The SRT starts with the individual's affective and physiological state (e.g. stressed/unstressed) prior to interacting with the natural environment. This initial state will determine what features of the environment are perceived (Ulrich 1983). According to the theory, visual perception of the natural environment will initiate an immediate, general affective reaction (e.g. like/dislike) and automatic approach-avoidance behavioural responses (Ulrich 1983). This immediate emotional reaction subsequently influences cognitive appraisals of the scene in terms of its significance for well-being and personal safety. This cognitive appraisal may modify the initial, general affective reaction and will produce additional emotional responses, which in turn will influence a change in physiological arousal, and behaviour (Ulrich 1983).

For example, an individual who is stressed spends time in a natural environment. This environment contains visual stimuli that facilitate a general positive affective reaction (i.e. like) and automatic behavioural responses (i.e. approach or stay). Cognitive appraisal assesses the setting for its significance for well-being. The 
cognitive appraisal is positive, which results in positive emotional responses, and a reduction in negative emotions. These emotions may result in a change in physiological arousal, which could foster feelings of relaxation. Behavioural responses are to approach, explore or continue with one's activities in this environment.

\subsubsection{Connection to Biodiversity in the SRT}

According to SRT, there are visual qualities of the natural environment that facilitate these restorative responses. These visual qualities are: moderate to high complexity (i.e. number of independently perceived elements in a setting); a focal point in the setting to attract or direct attention; moderate to high level of depth (or openness); a smooth and even ground surface that is conducive for movement; a lack of threat; and presence of a deflected vista (e.g. path bending away) and water (Ulrich 1983). Biodiversity can be considered as a measure of an environment's complexity (Ulrich 1983 p. 96). Based on Berlyne's aesthetic model (see Sect. 7.2.1), Ulrich (1983, p. 97) speculated that high (e.g. 'a thicket') and low levels (e.g. 'a flat, featureless open field') of complexity would not be preferred and generate an immediate emotional reaction of dislike and low interest. From this, it is reasonable to assume that environments with moderate levels of complexity would be restorative as they would be preferred, have an immediate emotional reaction of like and interest, and behavioural responses to stay or explore in the environment.

Researchers have investigated whether biodiverse environments could facilitate restorative outcomes associated with SRT. Inconsistent results have been found. Fractal dimensions of habitats with varying levels of species richness were negatively correlated with physiological arousal, suggesting that physiological arousal is related to the fractal dimension of a natural landscape (Stevens 2018) (see Sect. 7.2.3). Greater perceived species richness of animals/plants was associated with more positive mood and arousal, suggesting that higher perceived levels of biodiversity are associated with higher restorative outcomes related to SRT (White et al. 2017). In an experimental study, participants' positive affect, vitality and anxiety were assessed after viewing pictures of trees and birds with either low or high biodiversity (Wolf et al. 2017). Participants reported higher levels of positive affect, as well as lower levels of anxiety, in the high species-richness conditions of trees and birds, compared to low species-richness conditions; no effect was found for vitality between the high and low species-richness conditions of birds and trees. The level of biodiversity of fish and crustaceans in an aquarium had no effect on participants' heart rate, blood pressure and mood (Cracknell et al. 2016). In a separate study, pictures of fish and crustaceans with low or high species richness had no effect on happiness, when abundance of fish and crustaceans was held constant (Cracknell et al. 2017). Ensinger and von Lindern (2018) found that wilderness environments facilitated greater positive arousal, but no change in negative arousal, compared to other landscape types (see Box 7.4). See Korpela et al. (2018) for a deeper examination of studies investigating biodiversity and SRT outcomes. 


\subsubsection{Attention Restoration Theory (ART)}

Attention restoration theory (ART) emphasises restoration of one's ability to concentrate or direct attention (Kaplan and Kaplan 1989; Kaplan 1995; Kaplan and Talbot 1983). Defining aspects of ART are highlighted in Box 7.3. Directed attention is important to human functioning because it is an executive cognitive function, which controls the ability to process information, working memory, inhibitory control, planning and problem solving (Kaplan 1995). The ability to direct attention is necessary for fulfilling a task (e.g. writing a report), and planning and managing behaviour (e.g. achieving life goals) (Kaplan 1995). However, the ability to direct attention is limited and can become fatigued due to continuous and prolonged use (Kaplan and Kaplan 1989). This depletion of the ability to concentrate is called directed attention fatigue. Consequences of directed attention fatigue include the inability to solve problems, impaired perception, impulsive behaviour, irritability with others and errors in one's work (Kaplan and Kaplan 1989; Kaplan 1995).

Restoration of directed attention fatigue requires person-environment transactions that can facilitate the experience of four experiential qualities: fascination, being away, coherence/extent and compatibility (Kaplan and Kaplan 1989; Kaplan 1995). In order to restore the ability to direct attention, a person needs to use a mode of attention that does not require any cognitive effort, called effortless attention. Environments with interesting stimuli that effortlessly attract one's attention will facilitate the experience of fascination. Examples of such fascinating stimuli are: "strange things, moving things, wild animals, bright things, pretty things..." (James 1892). Fascination can be sustained if the stimuli in the environment are organised in a coherent way and are rich enough to foster the experience of being in a whole other world (coherence). The theory also recognises that there needs to be a match between the environmental setting and one's purposes and inclinations; a compatible environment allows one to carry out his or her activities without struggle (compatibility). Finally, a restorative environment requires one to experience physical or psychological distance from everyday tasks or demands that draw upon directed attention (being away). Taken together, these four experiential qualities allow

\section{Box 7.3: Defining Features of Attention Restoration Theory}

- The ability to direct attention is an executive cognitive function that can become fatigued through overuse.

- The inability to concentrate or focus attention is a sign of directed attention fatigue.

- Restoration from directed attention fatigue requires an individual to experience a sense of being away, fascination, coherence and compatibility in a specific environment.

- Natural environments tend to afford an experience of these four restorative qualities. 
people to rest and recover their ability to direct attention. Natural environments are theorised to be especially good environments for attention restoration, because natural environments have a high level of these four restorative qualities (Kaplan and Kaplan 1989; Kaplan 1995).

\subsubsection{Connection to Biodiversity in the ART}

Biodiversity was not a concept that was used in the original theoretical writings of the ART. However, using the theory, one could hypothesise that more biodiverse natural environments may be better environments for restoring directed attention as they may contain fascinating stimuli and afford the experience of being away. Indeed, the relationship between biodiverse environments and the four experiential restorative qualities of ART has been investigated. A significant, positive association between the objectively assessed level of biodiversity and all four qualities of a restorative environment has been found (Scopelliti et al. 2012). However, small urban green spaces rich in plant and animal species were found to be positively related to coherence, but negatively related to fascination, and not related to being away or compatibility (Peschardt and Stigsdotter 2013). Examing perceived biodiversity, Marselle et al. (2016) found perceived biodiversity of birds was positively associated with being away, fascination and compatibility, but not coherence (Marselle et al. 2016). Whereas, perceived biodiversity of plants/trees and butterflies were not related to any restorative qualities (Marselle et al. 2016). Foo (2016) investigated the mediating pathways between spending time in forest environments with low, medium or high levels of biodiversity, and mental health. Individuals who spent time in medium or high biodiverse forest environments experienced a sense of being away, which was positively associated with a change in mood, which then was related to improved mental health. This multiple mediation pathway was not found in the low biodiverse forest. Significant, positive associations between objectively assessed level of biodiversity and perceived restorativeness - a composite measure of all four experiential qualities - have also been found (Scopelliti et al. 2012; Carrus et al. 2015). Measuring biodiversity indirectly by investigating different landscape types in the Black Forest National Park, Ensinger and von Lindern (2018) found significantly greater fascination, being away and compatibility from walking in wilderness compared to other types of landscapes (see Box 7.4).

Researchers have also investigated whether biodiversity could facilitate restoration as an outcome - without investigating the specific four experiential qualities of ART. White et al. (2017) found greater perceived species richness of animals/plants was positively associated with perceived restorative potential. As the level of biodiversity perceived in the environment increased, more participants reported that the environment would be good for restoration. However, Cracknell et al. (2017) found that abundance of all fish/crustaceans, and not the number of species, influenced participants' perception of the scene as restorative. See Korpela et al. (2018) for further details of studies examining biodiversity and ART outcomes. 


\section{Box 7.4: Health Benefits of Experiencing Wilderness - Case Study in the Black Forest National Park}

Kerstin Ensinger $(\bowtie)$

Black Forest National Park, Seebach, Germany

e-mail: kerstin.ensinger@nlp.bwl.de

Eike von Lindern

Dialog N - Research and Communication for People, Environment and Nature, Zurich, Switzerland

e-mail: eike.von.lindern@dialog-n.ch

The Black Forest National Park is surrounded by densely populated areas, like the city of Stuttgart. It serves as both a refuge for wildlife and endangered species, and as a recreational area for the local population and tourists. Thus, its management objectives comprise both nature conservation and increasing human health and well-being via recreation opportunities. In 2016, the Black Forest National Park conducted an experimental study to explore the association between experiencing different types of natural landscapes and human health. Participants $(n=111)$ followed a pre-defined path that led through four landscape types: a cultivated spruce forest; a small trail with blueberry vegetation; open heathland; and a pristine forest (referred to as 'wilderness'). At designated stops within each of the different landscapes, participants reported their experience of the four restorative qualities of ART, and the SRT outcomes of positive and negative arousal (for details see Ensinger and von Lindern 2018).

While perceiving the landscape associated with 'wilderness', the participants experienced significantly more fascination compared to the other three landscapes. Ratings for being away and compatibility were stronger compared to the 'cultivated forest of spruce', but not significantly different from the 'small trail with blueberry vegetation' nor the 'open heathland'. Most striking, coherence was rated significantly lower in the wilderness setting compared to the other three landscapes (see Fig. 7.3).

Positive arousal was significantly higher in wilderness compared to the other three landscapes, but no differences emerged for negative arousal.

Among other results reported elsewhere (Ensinger and von Lindern 2018), the overall findings suggest that experiencing wilderness in National Parks and designated protected areas makes a unique and positive contribution to stronger restorative outcomes. Thus, the results can inform management plans that aim at complementing nature conservation with human health promotion. 
4

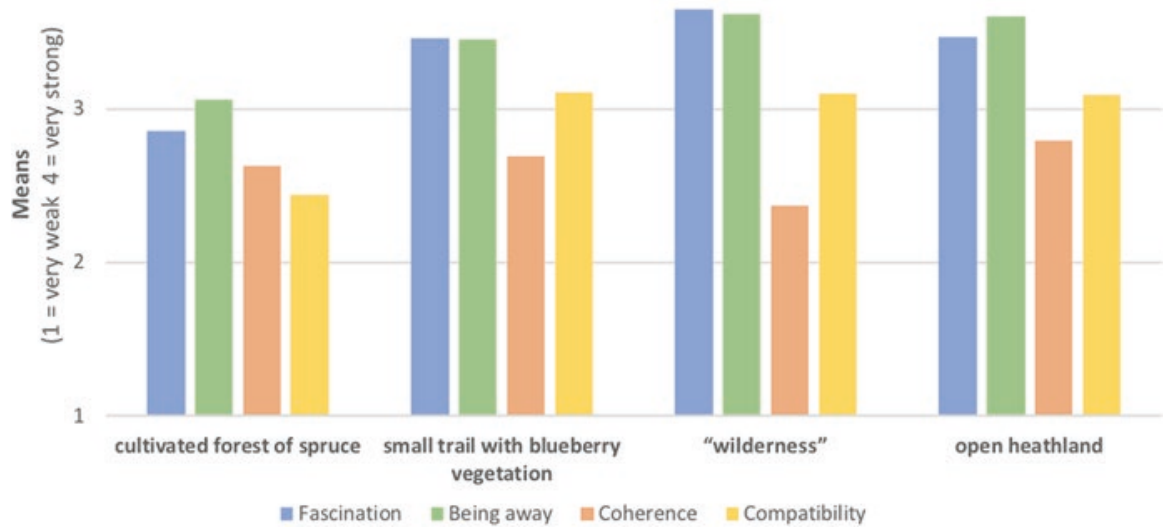

Fig. 7.3 Mean ratings for perception of restorative qualities for different types of landscape in the Black Forest National Park $(n=86)$

\subsection{Ecosystem Services Cascade Model}

The Ecosystem Service Cascade Model details the links between biodiversity and human well-being (Haines-Young and Potschin 2010; Potschin and Haines-Young 2011). The model proposes causal pathways through which biodiversity benefits human well-being through ecosystem functions and services (Potschin and HainesYoung 2011) (see Fig. 7.4). These causal pathways are described as steps that cascade into one another. According to the Cascade Model, biophysical structures or processes are responsible for ecosystem functions, and ecosystem functions influence ecosystem services, which, in turn, result in ecosystem benefits.

The Ecosystem Service Cascade Model has an anthropocentric and utilitarian viewpoint of nature, meaning that an ecosystem service can only be a service if humans experience that service to be useful and beneficial (Haines-Young and Potschin 2010; Potschin and Haines-Young 2011). Thus, an ecosystem service is not a fundamental property of the ecosystem itself, but something that is useful to humans (Haines-Young and Potschin 2010). The Convention of Biological Diversity (United Nations Convention of Biological Diversity 1992) considers ecosystem services as a matter of societal choice in which different sectors of society may derive different economic, cultural and societal needs from ecosystems. Therefore, ecosystem services are not isolated from people's needs (Haines-Young and Potschin 2010) and are defined as "something that changes the level of [human] well-being" (Haines-Young and Potschin 2010, p. 117). An ecosystem benefit is "something that directly impacts on the welfare of the people" (Haines-Young and Potschin 2010, p. 117). Ecosystem benefits represent the many ways biodiversity can contribute to human well-being (Mace et al. 2012) through, for example, regulation of water quality for better drinking water, a more satisfying fishing trip (Haines-Young and Potschin 2010), improved human health (Sandifer et al. 2015) or increased feelings 


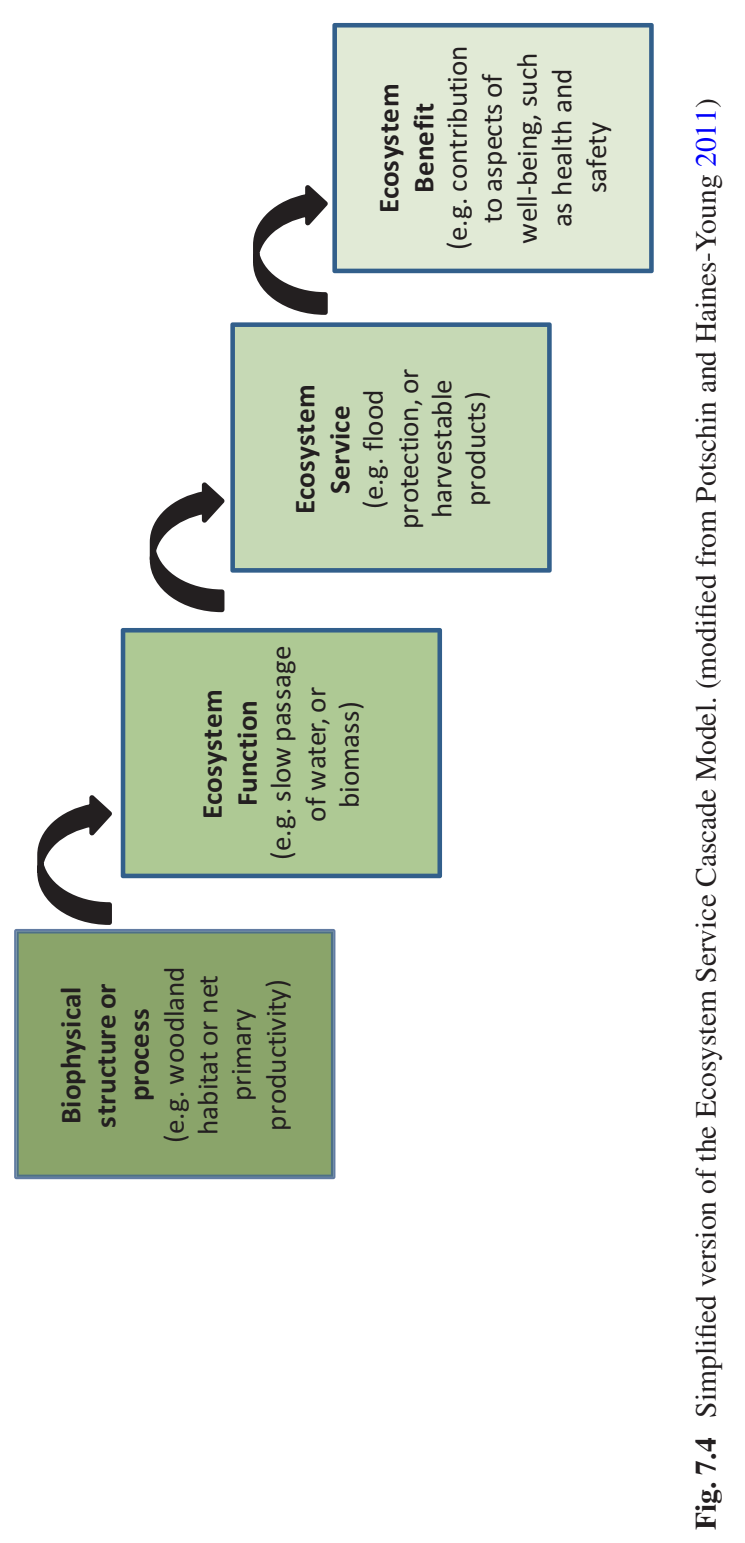


of safety (Potschin and Haines-Young 2011). From this perspective, the cascade model can also work upstream, from the ecosystem benefit to its related ecosystem function. For example, if human beings receive a benefit from a nature-based solution for flood protection, then that flood protection measure is considered to be an ecosystem service, and its related function (e.g. slow passage of water) can be considered an ecosystem function (Potschin and Haines-Young 2011).

Importantly, biodiversity can have different roles in this cascade. Biodiversity can serve as a regulator of the underpinning ecosystem processes (e.g. through pollinating insects), as an ecosystem service (e.g. as a harvestable crop that provides food or timber) or as a benefit (e.g. an emblematic species that is valued for its aesthetics, and may be enjoyed through wildlife watching) (Mace et al. 2012). While mechanisms and linkages between biodiversity, ecosystem functions and ecosystem services are still being explored (Cardinale et al. 2012), and there has been a recent debate over the terminology and the utilitarian viewpoint of the ecosystem service approach (Díaz et al. 2018; Peterson et al. 2018), the Ecosystem Service Cascade Model still holds.

\subsubsection{Connection to Health and Well-being in the Ecosystem Service Cascade Model}

Human well-being is not explicitly discussed in the Ecosystem Service Cascade Model. Instead, the Model focuses on benefits derived from biodiversity and ecosystem services. Most of the research on the benefits of ecosystem services for human health and well-being focusses on the physical health benefits from provisioning and regulating ecosystem services (Sandifer et al. 2015). However, a developing area of literature investigates the mental well-being benefits from cultural ecosystem services (e.g. Bryce et al. 2016; Fish et al. 2016; Hegetschweiler et al. 2017; O'Brien et al. 2017). The exact casual pathways linking biodiversity to physical and mental health and well-being through the Cascade Model are little understood (Sandifer et al. 2015).

\subsection{Discussion}

Interest in the mental health and well-being benefits from biodiversity is growing (see Marselle et al. Chap. 9, this volume). This chapter presents a general description of six frameworks that can offer perspective on the relationships between biodiverse natural environments and mental well-being. The aim was to provide an overview of these frameworks to enable future researchers to theoretically ground their investigations of biodiversity and mental well-being relationships. The frameworks are largely from the field of environmental psychology and represent the majority of theories used in biodiversity and health research (Lovell et al. 2014). Table 7.2 provides a summary of these six frameworks. 
Table 7.2 Summary of the six frameworks offering perspective on biodiversity and mental wellbeing relationships with descriptions of how biodiversity and mental well-being are conceptualised, and the mediating pathways that could explain biodiversity-health relationships

\begin{tabular}{|c|c|c|c|c|}
\hline Framework & Description & $\begin{array}{l}\text { Biodiversity } \\
\text { conceptualisation }\end{array}$ & $\begin{array}{l}\text { Mental well-being } \\
\text { conceptualisation }\end{array}$ & $\begin{array}{l}\text { Mediating } \\
\text { pathways }\end{array}$ \\
\hline $\begin{array}{l}\text { Preference } \\
\text { Matrix }\end{array}$ & $\begin{array}{l}\text { Preferences for } \\
\text { environments } \\
\text { are based on } \\
\text { information the } \\
\text { environment } \\
\text { provides }\end{array}$ & $\begin{array}{l}\text { Four information } \\
\text { qualities in a } \\
\text { landscape are: } \\
\text { complexity; } \\
\text { coherence; legibility; } \\
\text { and mystery. } \\
\text { Biodiversity is } \\
\text { implicitly considered } \\
\text { as a measure of an } \\
\text { environment's } \\
\text { complexity, which } \\
\text { refers to the 'richness' } \\
\text { of a visual scene }\end{array}$ & $\begin{array}{l}\text { Preference, or } \\
\text { liking, for a specific } \\
\text { environment or } \\
\text { landscape }\end{array}$ & $\begin{array}{l}\text { Informational } \\
\text { needs of } \\
\text { understanding and } \\
\text { exploration }\end{array}$ \\
\hline $\begin{array}{l}\text { Fractal } \\
\text { Geometry }\end{array}$ & $\begin{array}{l}\text { Shapes, } \\
\text { processes or } \\
\text { systems that } \\
\text { contain } \\
\text { repeating } \\
\text { patterns that are } \\
\text { reduced-size } \\
\text { copies of the } \\
\text { whole }\end{array}$ & $\begin{array}{l}\text { Natural phenomena, } \\
\text { such as coastlines, } \\
\text { rivers, trees, leaves } \\
\text { and snowflakes, are } \\
\text { fractal. Fractals have } \\
\text { been used to } \\
\text { determine biodiversity } \\
\text { of an environment }\end{array}$ & $\begin{array}{l}\text { Preference for, or } \\
\text { liking, a specific } \\
\text { visual landscape }\end{array}$ & $\begin{array}{l}\text { Perceptual } \\
\text { fluency - the ease } \\
\text { with which a } \\
\text { specific visual } \\
\text { stimulus is } \\
\text { perceptually } \\
\text { processed. } \\
\text { Fractals contain } \\
\text { redundant } \\
\text { information, due } \\
\text { to their self- } \\
\text { similar repeating } \\
\text { patterns, which } \\
\text { could contribute } \\
\text { to the experience } \\
\text { of easy perceptual } \\
\text { processing by the } \\
\text { brain }\end{array}$ \\
\hline $\begin{array}{l}\text { Biophilia } \\
\text { Hypothesis }\end{array}$ & $\begin{array}{l}\text { Humans have } \\
\text { an innate, } \\
\text { emotional } \\
\text { connection to } \\
\text { life and life-like } \\
\text { processes, } \\
\text { which motivates } \\
\text { contact with } \\
\text { animals, plants } \\
\text { and natural } \\
\text { landscapes }\end{array}$ & $\begin{array}{l}\text { Posits that biodiversity } \\
\text { and certain landscapes } \\
\text { engender optimal } \\
\text { human functioning. } \\
\text { Does not specify } \\
\text { which species or } \\
\text { landscape types are } \\
\text { best for Biophilia. }\end{array}$ & $\begin{array}{l}\text { Preference for } \\
\text { animals, plants or } \\
\text { environments }\end{array}$ & Learning theory \\
\hline
\end{tabular}


Table 7.2 (continued)

\begin{tabular}{|c|c|c|c|c|}
\hline Framework & Description & $\begin{array}{l}\text { Biodiversity } \\
\text { conceptualisation }\end{array}$ & $\begin{array}{l}\text { Mental well-being } \\
\text { conceptualisation }\end{array}$ & $\begin{array}{l}\text { Mediating } \\
\text { pathways }\end{array}$ \\
\hline $\begin{array}{l}\text { Stress } \\
\text { Reduction } \\
\text { Theory } \\
\text { (SRT) }\end{array}$ & $\begin{array}{l}\text { Environments } \\
\text { facilitate } \\
\text { recovery from } \\
\text { physiological } \\
\text { arousal and } \\
\text { psychological } \\
\text { stress }\end{array}$ & $\begin{array}{l}\text { Restorative } \\
\text { environments are } \\
\text { characterised by } \\
\text { visual characteristics: } \\
\text { moderate complexity; } \\
\text { moderate depth; a } \\
\text { focal point; deflected } \\
\text { vistas (e.g. path } \\
\text { bending away); a } \\
\text { ground surface } \\
\text { conducive for } \\
\text { movement; lack of } \\
\text { threat; and water. } \\
\text { Biodiversity is } \\
\text { considered to be a } \\
\text { measure of an } \\
\text { environment's } \\
\text { complexity }\end{array}$ & $\begin{array}{l}\text { Reduced } \\
\text { physiological } \\
\text { arousal, } \\
\text { psychological stress } \\
\text { and reduced } \\
\text { negative affect, and } \\
\text { enhanced positive } \\
\text { affect }\end{array}$ & $\begin{array}{l}\text { Autonomic } \\
\text { nervous system }\end{array}$ \\
\hline $\begin{array}{l}\text { Attention } \\
\text { Restoration } \\
\text { Theory } \\
\text { (ART) }\end{array}$ & $\begin{array}{l}\text { Person- } \\
\text { environment } \\
\text { transactions in } \\
\text { environments } \\
\text { facilitate } \\
\text { restoration from } \\
\text { directed } \\
\text { attention fatigue }\end{array}$ & $\begin{array}{l}\text { A restorative } \\
\text { environment is one } \\
\text { that requires little } \\
\text { cognitive effort. } \\
\text { Natural environments } \\
\text { are more likely to } \\
\text { permit and promote } \\
\text { restoration. } \\
\text { Biodiversity is not } \\
\text { explicitly considered }\end{array}$ & $\begin{array}{l}\text { Ability to } \\
\text { concentrate or } \\
\text { direct attention. } \\
\text { This is an executive } \\
\text { cognitive function, } \\
\text { required to process } \\
\text { information, and } \\
\text { inhibit and plan } \\
\text { behaviour and } \\
\text { problem solving }\end{array}$ & $\begin{array}{l}\text { Experiential } \\
\text { qualities between } \\
\text { the person and the } \\
\text { environment will } \\
\text { help restore } \\
\text { directed attention: } \\
\text { fascination; } \\
\text { coherence; } \\
\text { compatibility and; } \\
\text { being away }\end{array}$ \\
\hline $\begin{array}{l}\text { Ecosystem } \\
\text { Service } \\
\text { Cascade }\end{array}$ & $\begin{array}{l}\text { Model details } \\
\text { the links } \\
\text { between } \\
\text { biodiversity and } \\
\text { human values } \\
\text { through } \\
\text { ecosystem } \\
\text { services }\end{array}$ & $\begin{array}{l}\text { Any biophysical } \\
\text { structure or process. } \\
\text { But biodiversity can } \\
\text { also be part of an } \\
\text { ecosystem function } \\
\text { and ecosystem service }\end{array}$ & $\begin{array}{l}\text { Ecosystem service } \\
\text { benefit is described } \\
\text { as "something that } \\
\text { directly impacts on } \\
\text { the welfare of } \\
\text { people" }\end{array}$ & $\begin{array}{l}\text { Ecosystem } \\
\text { functions and } \\
\text { ecosystem } \\
\text { services }\end{array}$ \\
\hline
\end{tabular}

Which Theories Address Biodiversity? Biodiversity is explicitly considered in fractal geometry, the Biophilia Hypothesis, and the Ecosystem Service Cascade Model. Fractal dimensions have been used to determine habitat quality (Imre and Bogaert 2004), landscape structure and composition (Pe'er et al. 2013), habitat complexity (Dibble and Thomaz 2009) and species richness of an area (Stevens 2018). The Biophilia Hypothesis posits a preference for animals, plants and natural environments, but it does not specify which species or landscape types are best for fulfilling the biophilic need for connection to nature (Sundli Tveit et al. 2013). Further, the strongest work on the Biophilia Hypothesis is with its opposite, biophobia, the fear of specific animals and landscapes (Ulrich 1993). The Ecosystem 
Service Cascade Model defines biodiversity as any biophysical structure or process (Potschin and Haines-Young 2011), and biodiversity can take on different roles in the cascade (Mace et al. 2012).

Biodiversity is not explicitly discussed in the Preference Matrix, SRT and ART. In both the Preference Matrix and SRT, the term 'complexity' is used, which could be considered as a proxy for biodiversity; both frameworks define complexity as the number of independently different visual elements in a setting (Kaplan and Kaplan 1989; Ulrich 1983). This suggests that a biodiverse environment could be a complex environment due to having a greater number of independently different stimuli (i.e. species; Korpela et al. 2018) and, indeed, Ulrich (1983) specifically states that biodiversity can be considered a measure of an environment's complexity. ART does not discuss biodiversity. As such, one has to hypothesise how biodiversity could be applied to the ART; for example, an environment with a greater number of different species may contain fascinating stimuli and afford the experience of being away (Marselle et al. 2016; Korpela et al. 2018). This hypothesis has empirical support (see Sect. 7.3.2.1).

Which Theories Address Mental Well-Being? Mental well-being is discussed in the ART and SRT. Both the ART and SRT are theories of restorative environments, which refer to the recovery of physiological or psychological resources that have been diminished through the demands of dealing with everyday life (Hartig et al. 2011; von Lindern et al. 2016). Over time, lack of restoration of these resources can lead to mental and physical ill health (Hartig et al. 2011; von Lindern et al. 2016). Health and well-being in the ART is the restoration of the ability to concentrate or direct attention. In SRT, health and well-being is considered as the recovery from psychological and physiological stress reactions.

Mental well-being is not explicitly discussed in the Preference Matrix, fractals, Biophilia Hypothesis and the Ecosystem Service Cascade Model. The first three of these frameworks are environmental preference models. Preference can signal that certain natural stimuli could possibly contribute to health or well-being (Hartig et al. 2011), but cannot in itself be considered a health or well-being outcome (Lovell et al. 2014). Recent studies on fractals are finding that visual fractal objects may contribute to attention restoration (Hagerhall et al. 2015) and physiological arousal (Stevens 2018). The Ecosystem Service Cascade Model discusses human health and wellbeing as benefits derived from biodiversity and ecosystem services (Haines-Young and Potschin 2010; Potschin and Haines-Young 2011), but little research links ecosystem services to human health and well-being (Sandifer et al. 2015).

Which Frameworks Discuss Mediating Pathways? All six frameworks detail the mediating pathways of the relationships between nature and health. These same mediating pathways could also account for biodiversity and mental well-being relationships. The Preference Matrix suggests that informational needs of understanding and exploration mediate the relationship between informational qualities (e.g. complexity) and preference. Frameworks on fractals in nature suggest that perceptual fluency, the ease of cognitively processing a visual stimulus, would explain 
relationships between fractals in nature and preference. This work on perceptual fluency can also contribute to the restorative outcomes discussed in the ART. The Biophilia Hypothesis proposes that the learning theory can explain preferences for certain animals and plants. The SRT posits that nature-health relationships are mediated through the autonomic nervous system. The ART states that experiencing four experiential, person-environment qualities (being away, fascination, coherence/extent and compatibility) are required for attention restoration. In the Ecosystem Service Cascade Model, the relationship between biodiversity properties and human benefit is mediated through biophysical structures or processes, ecosystem functions and ecosystem services in serial. But as biodiversity itself can occur in any stage of the Ecosystem Service Cascade Model, it is still unclear what are the exact casual pathways linking biodiversity to health and well-being (Sandifer et al. 2015).

Conclusion There does not appear to be a single, precise framework to describe biodiversity and mental well-being relationships, as none of the six frameworks discussed in this chapter fully describe either biodiversity or mental well-being outcomes. This is likely an artefact of the way in which the majority of these frameworks have been empirically tested, i.e. by comparing man-made and natural environments (Bowler et al. 2010; Thompson Coon et al. 2011). Natural environments, in these studies, are generally treated as uniform without consideration of their biological quality (Dallimer et al. 2012); in other words, the biodiversity of an environment was not explicitly investigated. Recently, a few researchers have started to test these frameworks using biodiverse environments or stimuli. However, issues still remain about using frameworks largely developed to describe differences in natural or built settings to examine biodiverse environments and specific species.

As this inter-disciplinary field develops, it is important for researchers to challenge these existing frameworks. Future researchers could empirically test these frameworks using environments with varying levels of species diversity. Such research can help determine which frameworks are fit for purpose for describing the inter-relationships between biodiversity and mental well-being. Only through this theoretically grounded research can the existing frameworks be 'evolved' to better fit biodiversity and mental well-being relationships.

Acknowledgements Thanks are due to Professor Aletta Bonn for her guidance on the Ecosystem Service Cascade Model and Dr. Katherine Irvine for her recommendations on shaping the chapter. I am grateful to the four peer reviewers and Eike von Lindern for their helpful suggestions.

\section{References}

Bell PA, Greene TC, Fisher JD, Baum A (2001) Environmental psychology. Harcourt, Fort Worth Berlyne DE (1960) Conflict, arousal and curiosity. McGraw-Hill, New York

Berlyne DE (1974) Studies in the new experimental aesthetics: steps toward an objective psychology of aesthetic appreciation. Halsted Press, New York 
Bies AJ, Blanc-Goldhammer DR, Boydston CR, Taylor RP, Sereno ME (2016) Aesthetic responses to exact fractals driven by physical complexity. Front Hum Neurosci 10:1. https://doi. org/10.3389/fnhum.2016.00210

Bourke P (1991) An introduction to fractals. http://paulbourkenet/fractals/fracintro/. Accessed 26 Feb 2018

Bowler DE, Buyung-Ali L, Knight T, Pullin AS (2010) A systematic review of evidence for the added benefits to health of exposure to natural environments. BMC Public Health 10:456. https://doi.org/10.1186/1471-2458-10-456

Bryce R, Irvine KN, Church A, Fish R et al (2016) Subjective Well-being indicators for large-scale assessment of cultural ecosystem services. Ecosyst Serv 21:258-269

Cardinale BJ, Duffy JE, Gonzalez A et al (2012) Biodiversity loss and its impact on humanity. Nature 486:59-67. https://doi.org/10.1038/nature11148

Carrus G, Scopelliti M, Lafortezza R et al (2015) Go greener, feel better? The positive effects of biodiversity on the Well-being of individuals visiting urban and peri-urban green areas. Landscape Urban Plan 134:221-228

Cracknell D, White MP, Pahl S, Nichols WJ, Depledge MH (2016) Marine biota and psychological Well-being: a preliminary examination of dose-response effects in an aquarium setting. Environ Behav 48(10):1242-1269. https://doi.org/10.1177/0013916515597512

Cracknell D, White MP, Pahl S, Depledge MH (2017) A preliminary investigation into the restorative potential of public aquaria exhibits: a UK student-based study. Landsc Res 42(1):18-32. https://doi.org/10.1080/01426397.2016.1243236

Dallimer M, Irvine KN, Skinner AMJ et al (2012) Biodiversity and the feel-good factor: understanding associations between self-reports human Well-being and species richness. Bioscience 62(1):47-55

Díaz S, Pascual U, Stenseke M et al (2018) Assessing nature's contributions to people. Science 359:270-272

Dibble ED, Thomaz SM (2009) Use of fractal dimension to assess habitat complexity and its influence on dominant invertebrates inhabiting tropical and temperate Macrophytes. J Freshw Ecol 24(1):93-102

Ensinger K, von Lindern E (2018) Wie wird Natur erlebt? Pilotstudie zum Naturerleben im Nationalpark Schwarzwald [How is nature perceived? Pilot-study regarding the experience of nature in the Black Forest National Park]. Black Forest National Park, Seebach

Fish R, Church A, Winter M (2016) Conceptualising cultural ecosystem services: a novel framework for research and critical engagement. Ecosyst Serv 21:208-217

Foo CH (2016) Linking forest naturalness and human wellbeing-a study on public's experiential connection to remnant forests within a highly urbanized region in Malaysia. Urban For Urban Green 16:13-24

Frame M, Mandelbrot B, Neger, N (n.d.) Introduction to fractals. In: Fractal geometry http://users. math.yale.edu/public_html/People/frame/Fractals/. Accessed 26 Feb 2018

Hagerhall CM, Purcell T, Taylor R (2004) Fractal dimension of landscape silhouette outlines as a predictor of landscape preference. J Environ Psychol 24(2):247-255

Hagerhall CM, Laike T, Küller M et al (2015) Human physiological benefits of viewing nature: EEG responses to exact and statistical fractal patterns. Nonlinear Dynamics Psychol Life Sci 19(1):1-12

Haines-Young R, Potschin M (2010) The links between biodiversity, ecosystem services and wellbeing. In: Raffaelli DG, Frid CLJ (eds) Ecosystem ecology: a new synthesis. Cambridge University Press, Cambridge, pp 110-139

Hartig T, Evans GW (1993) Psychological foundations of nature experience. In: Garling T, Golledge RG (eds) Advances in psychology. Vol 96: Behavior and environment: psychological and geographical approaches. New Holland, Amsterdam, pp 427-457

Hartig T, van den Berg AE, Hagerhall CM et al (2011) Health benefits of nature experience: psychological, social and cultural processes. In: Nilsson K, Sangster M, Gallis C et al (eds) Forests, trees and human health. Springer, Dordrecht, pp 127-168 
Hedblom M, Heyman E, Antonsson H, Gunnarsson B (2014) Bird song diversity influences young people's appreciation of urban landscapes. Urban For Urban Green 13(3):469-474

Hegetschweiler KT, de Vries S, Arnberger A et al (2017) Linking demand and supply factors in identifying cultural ecosystem services of urban green infrastructures: a review of European studies. Urban For Urban Green 21:48-59

Ibanez JJ, Bockheim J (2013) Pedodiversity: state of the art and future challenges. CRC Press, Boca Raton

Imre AR, Bogaert J (2004) The fractal dimension as a measure of the quality of habitats. Acta Biotheor 52:41-56

Irvine KN, Warber SL, Devine-Wright P, Gaston KJ (2013) Understanding urban green space as a health resource: a qualitative comparison of visit motivation and derived effects among park users in Sheffield, UK. Int J Environ Res Public Health 10:417-442. https://doi.org/10.3390/ ijerph 10010417

James W (1892) Psychology: the briefer course. Holt, New York

Johansson M, Gyllin M, Witzell J, Küller M (2014) Does biological quality matter? Direct and reflected appraisal of biodiversity in temperate deciduous broad-leaf forest. Urban For Urban Green 13:28-37

Joye J, de Block A (2011) Nature and I are two': a critical examination of the Biophilia hypothesis. Environ Values 20(2):189-215. https://doi.org/10.3197/096327111X12997574391724

Joye Y, van den Berg A (2013) Restorative environments. In: Steg L, van den Berg AE, de JIM G (eds) Environmental psychology: an introduction. BPS Blackwell, West Sussex, pp 57-66

Joye Y, Steg L, Berfu Unal A, Pals R (2016) When complex is easy on the mind: internal repetition of visual information in complex objects is a source of perceptual fluency. J Exp Psychol Hum Percept Perform 42(1):103-114

Juliani AW, Bies AJ, Boydston CR et al (2016) Navigation performance in virtual environments varies with fractal dimension of landscape. J Environ Psychol 47:155-165

Kahn PJ (1997) Developmental psychology and the biophilia hypothesis: children's affiliation with nature. Dev Rev 17(1):1-61

Kaplan S (1995) The restorative benefits of nature: toward an integrative framework. J Environ Psychol 15(3):169-182

Kaplan R, Kaplan S (1989) The experience of nature: a psychological perspective. Cambridge University Press, Cambridge

Kaplan S, Talbot JF (1983) Psychological benefits of a wilderness experience. In: Altman I, Wohlwill JF (eds) Behavior and the natural environment. Plenum, New York, pp 163-203

Kellert SR (1993) Introduction. In: Kellert SR, Wilson EO (eds) The biophilia hypothesis. Island Press, Washington, DC, p 20

Korpela K, Pasanen T, Ratcliffe E (2018) Biodiversity and psychological well-being. In: Ossola A, Niemelä J (eds) Urban biodiversity. Routledge, New York, pp 134-149

Lindemann-Matthies P, Junge X, Matthies D (2010) The influence of plant diversity on people's perception and aesthetic appreciation of grassland vegetation. Biol Conserv 143:195-202

Lovell R, Wheeler BW, Higgins SL et al (2014) A systematic review of the health and wellbeing benefits of biodiverse environments. J Toxicol Environ Health B Crit Rev 17(1):1-20. https:// doi.org/10.1080/10937404.2013.856361

Mace GM, Norris K, Fitter AH (2012) Biodiversity and ecosystem services: a multilayered relationship. Trends Ecol Evol 27:24-31

Mandelbrot B (1983) The fractal geometry of nature. W.H. Freeman, New York

Marselle MR, Irvine KN, Lorenzo-Arribas A, Warber SL (2016) Does perceived restorativeness mediate the effects of perceived biodiversity and perceived naturalness on emotional Wellbeing following group walks in nature? J Environ Psychol 46:217-232

O'Brien L, De Vreese R, Kern M et al (2017) Cultural ecosystem benefits of urban and peri-urban green infrastructure across different European countries. Urban For Urban Green 24:236-248

Pe'er G, Zurita GA, Schober L et al (2013) Simple process-based simulators for generating spatial patterns of habitat loss and fragmentation: a review and introduction to the G-RaFFe model. PLoS One 8(5):e64968. https://doi.org/10.1371/journal.pone.0064968 
Peschardt KK, Stigsdotter UK (2013) Associations between park characteristics and perceived restorativeness of small public urban green spaces. Landscape Urban Plan 112:26-39

Peterson GD, Harmácková ZV, Meacham M et al (2018) Welcoming different perspectives in IPBES: "Nature's contributions to people" and "Ecosystem services". Ecol Soc 23(1):39. https:// doi.org/10.5751/ES-10134-230139

Potschin MB, Haines-Young RH (2011) Ecosystem services: exploring a geographical perspective. Prog Phys Geogr 35:575-594

Sandifer PA, Sutton-Grier AE, Ward BP (2015) Exploring connections among nature, biodiversity, ecosystem services, and human health and Well-being: opportunities to enhance health and biodiversity conservation. Ecosyst Serv 12:1-15

Scopelliti M, Carrus G, Cini F et al (2012) Biodiversity, perceived Restorativeness and benefits of nature: a study on the psychological processes and outcomes of on-site experiences in urban and Peri-Urban Green areas in Italy. In: Kabisch S, Kunath A, Schweizer-Ries P, Steinführer A (eds) Vulnerability, risks and complexity: impacts of global change on human habitats. Hogrefe Publishing, Gottingen, p 255

Spehar B, Clifford CWG, Newell BR, Taylor RP (2003) Universal aesthetics of fractals. Comput Graph 27:813-820

Stevens P (2018) Fractal dimension links responses to a visual scene to its biodiversity. Ecopsychology. https://doi.org/10.1089/eco.2017.0049

Sundli Tveit M, Ode Sang A, Hagerhall CM (2013) Scenic beauty: visual landscape assessment and human landscape perception. In: Steg L, van den Berg AE, de Groot JIM (eds) Environmental psychology: an introduction. BPS Blackwell, West Sussex, pp 37-46

Taylor R (2001) Architect reaches for the clouds: how fractals may figure in our appreciation of a proposed new building. Nature 410:18. https://doi.org/10.1038/35065154

Taylor RP, Spehar B, van Donkelaar P, Hagerhall CM (2011) Perceptual and physiological responses to Jackson Pollock's fractals. Front Hum Neurosci 5. https://doi.org/10.3389/ fnhum.2011.00060

Thompson Coon J, Boddy K, Stein K et al (2011) Does participating in physical activity in outdoor natural environments have a greater effect on physical and mental wellbeing than physical activity indoors? A systematic review. Environ Sci Technol 45(5):1761-1772. https://doi. org/10.1021/es102947t

Tokeshi M, Arakaki S (2012) Habitat complexity in aquatic systems: fractals and beyond. Hydrobiologia 685:27-47. https://doi.org/10.1007/s10750-011-0832-z

Ulrich R (1983) Aesthetic and affective response to natural environment. In: Altman I, Wohlwill $\mathrm{J}$ (eds) Human behavior and the natural environment. Plenum Press, New York, pp 85-125

Ulrich RS (1993) Biophilia, biophobia, and natural landscapes. In: Kellert SR, Wilson EO (eds) The biophilia hypothesis. Island Press, Washington, DC, p 73

Ulrich R, Simons R, Losito B et al (1991) Stress recovery during exposure to natural and urban environments. J Environ Psychol 11(3):201-230

United Nations Convention on Biological Diversity (1992) Convention on biological diversity. https://wwwcbdint/doc/legal/cbd-enpdf. Accessed 12 July 2018

van den Berg AE, Joye Y, Koole SL (2016) Why viewing nature is more fascinating and restorative than viewing buildings: a closer look at perceived complexity. Urban For Urban Green 20:397-401

Vaz AS, Kull CA, Kueffer C, Richardson DM, Vicente JR, Kühn I, Schröter M, Hauck J, Bonn A, Honrado JP (2017) Integrating ecosystem services and disservices: insights from plant invasions. Ecosyst Serv 23:94-107

von Lindern E, Lymeus F, Hartig T (2016) The restorative environment: a complementary concept for salutogenesis studies. In: Mittelmark MB, Sagy S, Eriksson M et al (eds) The handbook of Salutogenesis. Springer, New York, pp 181-195

White MP, Weeks A, Hooper T et al (2017) Marine wildlife as an important component of coastal visits: the role of perceived biodiversity and species behaviour. Mar Policy 78(80):89

Wilson EO (1984) Biophilia. Harvard University Press, Cambridge, MA 
Wilson EO (1993) Biophilia and the conservation ethic. In: Kellert SR, Wilson EO (eds) The biophilia hypothesis. Island Press, Washington, DC, p 31

Wohlwill JF (1968) Amount of stimulus exploration and preference as differential functions of stimulus complexity. Percept Psychophys 4:307-312

Wolf LJ, zu Ermgassen S, Balmford A, White M Weinstein N (2017) Is variety the spice of life? An experimental investigation into the effects of species richness on self-reported mental Wellbeing. PLoS One 12(1):e0170225. https://doi.org/10.1371/journal.pone.0170225

World Health Organisation \& Secretariat of the Convention on Biological Diversity (2015) Connecting global priorities: biodiversity and human health. A state of the knowledge review. http://www.who.int/globalchange/publications/biodiversity-human-health/en/

Open Access This chapter is licensed under the terms of the Creative Commons Attribution 4.0 International License (http://creativecommons.org/licenses/by/4.0/), which permits use, sharing, adaptation, distribution and reproduction in any medium or format, as long as you give appropriate credit to the original author(s) and the source, provide a link to the Creative Commons license and indicate if changes were made.

The images or other third party material in this chapter are included in the chapter's Creative Commons license, unless indicated otherwise in a credit line to the material. If material is not included in the chapter's Creative Commons license and your intended use is not permitted by statutory regulation or exceeds the permitted use, you will need to obtain permission directly from the copyright holder.

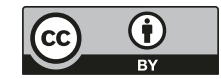

